\title{
A MORTE (E A VOLTA) DO LEITOR - OU DE COMO USAR A VOZ DO OUTRO PARA REFORÇAR DISTÂNCIAS NA AULA DE LITERATURA
}

Clarissa Menezes Jordão ${ }^{1}$

\begin{abstract}
RESUMO
Os professores de literatura costumam queixar-se da falta de interesse e da passividade dos alunos, reforçando uma imagem fortemente influenciada por uma determinada política de significação na formação das subjetividades dos alunos. Neste artigo discuto a possibilidade de interpretar o comportamento passivo e submisso dos alunos como um processo de formação de "habitus", em situações em que os alunos assimilam o discurso legitimado de seus professores e acabam por acreditar nele como a expressão de uma verdade sobre si mesmos. Eu argumento que os alunos (e os professores) precisam encontrar suas próprias vozes, que a linguagem oferece oportunidades de resistência e mudança, e que o conflito pode ser solo fértil para tais mudanças.
\end{abstract}

Palavras-chave: habitus, subjetividades, passividade, legitimação, oportunidade, resistência, mudança.

\begin{abstract}
Literature teachers often complain about the passivity and lack of motivation in their students, reinforcing an image which is strongly influenced by an unconscious policy of signification in the formation of the students subjectivities. In this article I discuss the possibility of interpreting students passive and subordinate behaviour as a process of "habitus" formation, in a situation in which students assimilate the legitimised discourse of their teachers and end up by believing in it as the expression of an inner truth about themselves. I hold that students (and teachers) need help in their quest for their own voices, that language itself presents them with opportunities of resistance and change, and that conflict can be seen as a fertile ground for changes.
\end{abstract}

Key words: habitus, subjectivities, passivity, legitimation, opportunity, resistance, change.

Quando se propõe uma discussão sobre o ensino de literatura na universidade, tem-se como pressuposto que seja possível ensinar e aprender literatura em sala de aula. Eu, de minha parte, acredito que literatura possa ser tanto ensinada (no sentido de ser possível chamar à atenção convenções literárias e interpretativas, assim como fazer perceber contextos culturais, históricos e sociais que envolvem não apenas obras literárias, mas o próprio momento histórico de leitura), quanto aprendida (através da capacidade de cada indivíduo de fazer associações, comparações e ligações; através de processos de leitura de textos e atribuição de significados; através da consciência da possibilidade de múltiplas leituras, da

\footnotetext{
${ }^{1}$ Clarissa Menezes Jordão é doutora em Letras, mestre em Literaturas de Língua Inglesa e formada em Letras Português e Inglês. Atualmente é professora de Língua Inglesa e Lingüística Aplicada na UFPR.
} 
confiança na capacidade individual de construção de interpretações pessoais mesmo após a exposição a pontos de vista - ou leituras - diferentes. Acredito também que o contato com literatura seja intrinsecamente bom, e deva portanto continuar sendo parte do currículo acadêmico. Embora o questionamento da importância da literatura no mundo contemporâneo seja legítimo, a literatura tem seu próprio valor como um processo efetivo de criação de sentidos, de desafio, de desnudamento e produção de proposições morais, estéticas e políticas.

Em uma discussão como esta proposta aqui, qualquer tentativa de centralidade ${ }^{2}$ cartesiana tradicional seria visível na necessidade de definir termos, de afirmar uma conceitualização do que se entende por literatura, que certamente viria ao lado de respostas absolutas a dúvidas pós-modernas, tais como se, e qual, ou quais, literaturas devem ser ensinadas/aprendidas, e por quem, quando e onde, para quem, e acima de tudo quem toma as decisões, o que está por trás das decisões tomadas, e suas implicações pedagógicas (e portanto políticas). Talvez o modo mais seguro e certamente o mais rápido para a abordagem destas questões fosse transferir a responsabilidade pelas escolhas feitas à tradição propriamente dita $^{3}$, evitando polêmicas e aceitando o cânone, simplesmente porque ele foi instituído como tal; uma maneira fácil de sair do impasse seria presumir que professores sabem ensinar e alunos podem aprender, ignorando contextos sociais e idiossincrasias envolvidas no processo. Eu vou sair do dilema de outra maneira: como Saussure, afirmo reconhecer a existência do problema da parole, mas vou deixá-lo para estudos posteriores; minha preocupação no momento está na relação estabelecida entre os alunos e os textos, ou seja, em como os alunos recebem a imposição do cânone, e em como percebem suas comunidades interpretativas.

Para observar a percepção dos alunos em relação à imposição de leitura das obras selecionadas para as disciplinas, e também verificar como eles vêem a influência das comunidades interpretativas nos processos de significação a que submetem os textos literários, conduzi uma pesquisa piloto com alunos universitários de Letras ${ }^{4}$; perguntei a eles sobre a coincidência de suas próprias interpretações com as de outras pessoas, sobre a noção de pertencerem às comunidades interpretativas em que transitam. Esperava que dissessem não

\footnotetext{
${ }^{2}$ Estou me referindo ao conceito de estrutura de Derrida, por ele discutido em Writing and Difference. London: Routledge, 1995, esp. cap. “Structure, sign and play”.

${ }^{3}$ Cf. Gadamer sobre o papel da tradição, do conhecimento partilhado, de quadros de tradição ("frames of tradition) em GARDINER, M. The Dialogics of Critique, especialmente capítulo 4.

${ }^{4}$ As entrevistas aconteceram durante o mês de maio de 1997, com um total de 21 alunos e três professores. Oss alunos tinham experiência de leitura e backgrounds variados; três eram formandos, e os outros estavam cursando sua primeira ou segunda disciplina de literaturas em língua inglesa, todos eles tendo já cursado pelo menos outras duas disciplinas de literaturas em língua portuguesa.
} 
se enquadrar nos moldes comunitários: como "futuros intelectuais", sensíveis às peculiaridades das emoções humanas e às suas representações estéticas, deveriam sentir-se, pensava eu, deslocados, estranhamente diferentes do resto. Mas não, eles não se sentem à parte: não se vêem como especialmente diferentes de seus amigos e familiares, não se sentem “acadêmicos desajustados”. Os alunos até tentaram convencer-me de que gostam de ler, de que lêem sempre que possível, de que suas interpretações normalmente não são diferentes das do professor, dos críticos ou dos colegas. Entretanto, muitos disseram também que ficam em silêncio na sala de aula a maior parte do tempo, até que um colega mais proficiente em língua inglesa, ou mesmo o professor, verbalize as interpretações que eles próprios já fizeram, entretecendo-as com argumentos convincentes; os alunos mostram-se aparentemente tão integrados na comunidade interpretativa da sala de aula que, cedo ou tarde, dizem, algum colega acaba por expressar a leitura deles, só que se utilizando de "evidências” extraídas do texto. Ajustados? Participantes? Incorporados? Não seria esse “paraíso didático”, em que todos concordam com todos, o sintoma de um crença profunda no absolutismo do discurso da autoridade? Ou na autoridade do discurso? E se tais depoimentos forem contrapostos às várias vezes em que os alunos se referiram a discussões em sala como oportunidades para checarem se suas leituras estavam “certas” ou “erradas”? Não se teria aqui uma contradição aparente com a idéia de que tenham todos interpretações semelhantes?

Bem, meus leitores dialógicos estarão pensando, seres humanos não são mesmo coerentes, os sujeitos são fragmentados... Qual é o problema disso? O problema, caros leitores, é que tal fato passa despercebido: os alunos não têm consciência de tal fragmentação. Eles se vêem, ou querem se ver, como sujeitos monológicos, coerentes em suas interpretações; vêem seus professores como sujeitos monológicos, indivíduos que são a posição de professores, e não que ocupam tal posição, sujeitos cuja função é transmitir leituras “corretas” e ensinar os alunos a reproduzi-las; também vêem os textos como entidades monológicas, dos quais uma interpretação é preferível por ser a mais “correta”, a mais próxima da verdade. O problema, caro leitor, está em que os alunos não dizem isso explicitamente, mas fazem subentender; dizem que cada interpretação tem seu valor, mas não aceitam as interpretações dos colegas, a menos que sejam aceitas pelo professor; dizem que não alteram “muito” suas leituras em conseqüência das leituras de textos críticos ou das discussões em sala, mas que normalmente são convencidos pelos argumentos do professor a “expandir” suas interpretações. O poder dominador da voz do professor emerge freqüentemente no discurso dos alunos ao se referirem ao que acontece na sala de aula: a 
grande maioria dos alunos faz questão de deixar claro que não discorda das interpretações dadas pelo professor. Embora admitam às vezes ter uma certa dificuldade em aceitar a leitura do professor, acreditam que isso se deve mais à sua própria incapacidade de alcançar o conhecimento do professor, do que a um conflito entre processos de significação, e acabam rendendo-se à erudição do professor, aceitando como verdade absoluta o que ele tem a dizer sobre a interpretação das obras estudadas; na maior parte do tempo o professor é capaz de convencê-los usando bons argumentos, lógica e evidência textual, dizem, mas nas poucas vezes em que o professor não consegue provar que está certo, os alunos não se rebelam: simplesmente partem do pressuposto de que é o professor quem sabe "o que está certo”, "a verdade” sobre o assunto que está sendo discutido (talvez um termo melhor aqui fosse “transmitido”) e se os alunos não entendem, se eles não "vêem” elementos do texto, então é porque não alcançam o verdadeiro significado do texto, aquele significado que se encontra nas camadas mais profundas do imbricado tecido textual; é porque não conhecem as verdadeiras intenções do autor, cujo emissário é o professor; é porque pouco sabem sobre movimentos literários ou escolas de pensamento, e portanto suas interpretações podem ser descartadas como "erradas”, ou mal concebidas".

A aparente harmonia que os alunos tentaram veicular nas entrevistas serviu para alertarme sobre sua inconsciência em relação aos elementos envolvidos no contexto da sala de aula, bem como veio comprovar que as formações de poder/conhecimento a que se refere Foucault realmente constróem sujeitos através do discurso, pois como afirmam Usher \& Edwards, “Quando pessoas são construídas como determinados tipos de aprendizes, elas são definidas como tendo características que "pertencem" a elas; elas se tornam, em essência, pessoas daquele tipo.” (p.96)

Tal homogeneidade está muito longe do conceito de leitura como processo polifônico, como um processo que envolve perceber e escutar vozes diferentes, mover-se por várias comunidades interpretativas, por valores, pela história, pela humanidade. Ler literatura significa constituir discurso, estar imerso em sistemas de poder/conhecimento, assumir posições ideológicas, pois a neutralidade é utópica. Textos não são ilhas, “entire of themselves”: textos são redes de relações de poder/conhecimento, impregnados de e em

\footnotetext{
${ }^{5}$ Cf. Pennycook (1994), em uma discussão sobre o que Harris aponta como as duas falácias da lingüística moderna: "a idéia de que a linguagem reflete transparentemente tanto um mundo real ou os pensamentos de uma pessoa, quanto a crença de que comunidades lingüísticas partilham um código fixo através do qual elas comunicam significados semelhantes umas às outras.”(p.29, ) Isso reflete, de acordo com Harris, o objetivo educacional de “ 'padronizar o comportamento lingüístico dos alunos' ” (id., ibid).
} 
práticas sociais - discursos são modos de elaborar, organizar e limitar significados. ${ }^{6}$ Parece claro, nos comentários dos alunos nas entrevistas e em suas atitudes em sala de aula, que eles não partilham da visão de Bakhtin sobre a linguagem como uma arena de conflitos, diretamente relacionada a sistemas de poder. Os alunos parecem não perceber a natureza polifônica e dialógica da linguagem; eles vivem sob a impressão de que significados são absolutos, permanentes, e que professores, críticos, instituições têm a chave da porta da capela onde repousam os textos. Ao examinarmos esta visão ao lado da visão bakhtiniana da linguagem como fenômeno social, e portanto como um lugar onde muitas vozes diferentes existem em conflito dialógico, inevitavelmente ligado a questões de poder e ideologia, então compreenderemos o quanto a liberdade dos alunos em sala de aula é afetada por restrições sociais. O sujeito bakhtiniano, assim como a linguagem, é múltiplo, constituído por vários discursos em confronto perene e constante uns com os outros. O poder, conseqüentemente, é relativo, e não inerente a sujeitos ou instituições; o poder é sim caracterizado pela dominação, temporária e contingente, de um discurso sobre outros - tal contingência caracteriza o poder como provisório, frágil, passível de modificação. Assim, a oposição ao poder é sempre possível, e nos termos de Derrida, mesmo inerente à existência de qualquer ordem estabelecida. Não pode haver ordem sem desordem; no jogo de oposições, os extremos são “inseparáveis, imanentes um ao outro, cada um a condição para a possibilidade do outro" (Usher \& Edwards, p. 87); os significados são percebidos nas relações entre seus constituintes, cada um pressupondo e contendo seu oposto. A resistência, como parte de qualquer ordem estabelecida, está portanto sempre presente nas vozes conflitantes que constituem a linguagem e o sujeito.

Bakhtin também se refere a modos de resistência, e aponta o carnaval como exemplo de possibilidade de oposição através do riso, mostrando que se pode rir do status quo ainda que fazendo parte dele. Segundo Bakhtin, durante o Carnaval medieval, o poder dominante era institucionalmente satirizado, e conseqüentemente revelado como provisório através do jogo: o baile de máscaras, a inversão de papéis, a indefinição da hierarquia convencional representavam uma possibilidade momentânea de libertação das amarras da ordem social normalmente vigente. Tal fuga, porém, não leva à alteração efetiva da ordem social, mas apenas a uma inversão provisória de papéis, ou melhor, a uma troca temporária de atores para um mesmo papel. Todavia, a mera possibilidade de troca pode revelar a convencionalidade

\footnotetext{
${ }^{6}$ Cf. FOUCAULT, M. A Ordem do Discurso.
} 
das posições, a artificialidade dos papéis, e o fato de que não aponte para mudanças permanentes implica na exposição da mobilidade das relações de significação.

A escola como é hoje, ainda um espaço de disciplinarização, de hierarquia e de manutenção do estado de coisas, não suporta a instabilidade do carnaval, não consegue conviver com a incerteza e a angústia criadas pela possibilidade constante de mudanças. A educação objetiva eliminar a alteridade, reduzindo as diferenças e fixando significados. Ignorando a carnavalização bakhtiniana e o que Derrida chama de "jogo de différance”, a escola busca centrar interpretações, conferir valores absolutos a leituras institucionalizadas sem questionar essas "verdades" como socialmente construídas, e portanto relativas, temporárias, limitadas, sujeitas a estruturas de poder.

Usher \& Edwards referem-se ao poder autoritário e autorizante da educação, defendendo as leituras ${ }^{7}$ desconstrutivistas de Derrida como possibilidades de "intervenções

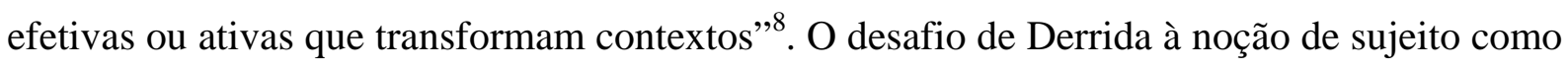
“fonte autenticadora original que conhece a si mesma por estar presente a si mesma e por não se deixar tocar pela alteridade” (p.146) abala o conceito de sujeito como o centro do mundo e centrado em si mesmo, substituindo-o pela idéia de um sujeito lacaniano que só pode se constituir em sua relação com os outros, pois "não nos fazemos de nós mesmos, mas somos formados nas significações da história, da cultura e das práticas discursivas” (id., ibid., p.147). A autonomia é assim relacionada à alteridade, dependente dela para ser compreendida.

Através da elaboração de suas próprias leituras (que obviamente não podem ser leituras absolutamente originais, mas sim produtos de uma maneira pessoal de integrar e associar o já conhecido), os alunos podem participar como agentes das relações de poder que dominam as salas de aula, resistindo e/ou aceitando os discursos acadêmicos não por recusa ou assentimento inocente, mas porque entendem o que está envolvido na atitude de um indivíduo às comunidades onde vive e pelas quais transita.

Quanto aos professores, não se espera deles simplesmente que dêem voz aos seus alunos, pois os alunos já têm sua própria voz; espera-se sim que os professores também desenvolvam uma atitude carnavalesca, ou seja, que também leiam os textos de modo pessoal, que permitam aos alunos e a si mesmos questionar o discurso acadêmico. Porém, auxiliando

\footnotetext{
${ }^{7}$ O conceito de leituras implícito aqui refere-se a noção de texto desenvolvida por Derrida, ou seja, “qualquer rede organizada de significados”, conforme discutida por USHER \& EDWARDS, p.144.

${ }^{8}$ Derrida, citado por USHER \& EDWARDS, p. 144.
} 
os alunos a “encontrar, desenvolver e criar [outras] vozes”(Pennycook, 1994(a), p.319), assim como possibilitando a expressão dessas vozes em sala de aula, os professores podem ajudar os alunos em seus processos de constituição das próprias subjetividades no jogo de différance. A idéia de "voz" usada aqui implica em

modos de nos fazer entender, de definir a nós mesmos como participantes ativos no mundo, tornando-nos agentes no processo de fazer história, fazendo as pazes com as relações complexas que informam a consciência e posicionam pessoas em relação a outras, movendo-se do silêncio à fala como um ato revolucionário ou oposicionista, lendo, escrevendo, falando, ouvindo contra a prática usual.(id., ibid., p.321, )

A compreensão do movimento dos processos de significação envolve risco e instabilidade, de vez que os significados são percebidos não como fixos ou estáveis, mas como móveis e instáveis, “fixados” contingencial e temporariamente; os sujeitos são constituídos num processo infinito de diferença e adiamento (différance), numa rede de relações, dialogicamente em conflito criativo. Situações em que não há conflitos, como aquelas descritas (talvez eu devesse escrever interpretadas) como harmônicas pela maioria dos alunos entrevistados, são utópicas, concebíveis apenas através da idéia da vida num vácuo onde nada existe, num buraco negro onde nada se movimenta, nada muda, um universo beckettiano onde a comunicação é impossível, onde o eu social é concebido como nãohistórico, e a linguagem totalmente desprovida do outro. Quando não se percebe o conflito, quando não se vê a necessidade de mudança, então o problema se apresenta muito mais sério, a imposição se faz muito mais radicalmente, e a ação se torna ao mesmo tempo mais difícil e mais premente. Diante de situações como esta, “não se pode cansar de falar”, como dizia meu avô comunista, pois a ilusão de harmonia é tão forte que impede a percepção dos problemas de fato, desviando a atenção para explicações ou justificativas imediatistas que apenas transferem-lhes as causas para uma região já conhecida, tentando esconder os problemas atrás de peneiras que não os impedem de passar. Transformar esses problemas que escapam pelos furos das peneiras em possibilidades de resistência, transformação e criação, sem perder de vista o fato de mesmo essas possibilidades serem sempre formas localizadas, contingentes e temporárias de poder, pode ser uma proposta de rebelião salutar contra as estruturas totalizantes que governam as salas de aula. 


\section{REFERÊNCIAS}

BAKHTIN, M. A Cultura Popular na Idade Média e no Renascimento: o contexto de François Rabelais. Brasília: Hucitec/Edunb, 1977.

. Estética da Criação Verbal. São Paulo: Martins Fontes, 1992.

Marxismo e Filosofia da Linguagem. São Paulo: Hucitec, 1988.

BURKE, S. The Death and Return of the Author: criticism and subjectivity in Barthes, Foucault and Derrida. Edinburgh: Edinburgh University Press, 1993.

CORACINI, M.J. (org.) O Jogo Discursivo na Aula de Leitura: língua materna e língua estrangeira. Campinas: Pontes, 1995.

DERRIDA, J. Writing and Difference. London: Routledge, 1995.

FAIRCLOUGH, N. "Michel Foucault and the Analysis of Discourse" In: Discourse and Social Change. Harlow: Longman, 1992.

Language and Power. Harlow: Longman, 1989.

FISH, S. Is There a Text in This Class?: the authority of interpretive communities. Cambridge: Harvard University Press, 1995 (9th ed).

FOUCAULT, M. “What’s an Author?” In: HARARI, J.V.(ed.) Textual Strategies. England: Methuen, 1979.

A Ordem do Discurso. São Paulo: Loyola, 1996.

GARDINER, M. The Dialogics of Critique. New York: Routledge, 1992. 
MAILLOUX, S. "Interpretive Conventions" In: Interpretive Conventions: the reader in the study of American fiction. London: Cornell University Press, 1984. p.140-158.

OITTINEN, Riitta. Victory over Fear: Literary Translation as a Carnivalistic Teaching Tool In: KÜMMERLING-MEIBAUER, Bettina. Compar(a)ison. An International Journal of Comparative Literature II. Bern-Berlin-Frankfurt: Peter Lang, 1995, pp. 49-65.

"The Verbal and The Visual: On the Carnivalism and Dialogics of Translating for Children” In: Teaching Translation and Interpreting Training, Talent and Experience. Amsterdam/Philadelphia: John Benjamins, 1992, pp. 75-80.

ORLANDI, E. Discurso e Leitura. Campinas: Cortez, 1996.

PENNYCOOK, A. “Incommensurable Discourses?” In: Applied Linguistics, 15 (2). Oxford: Oxford University Press, p.115-138, 1994. (a)

The Cultural Politics of English as an International Language. Harlow: Longman, 1994. (b)

USHER, R \& EDWARDS, R. Postmodernism and Education. London: Routledge, 1996. 